\title{
User acceptance of wireless short messaging services: Deconstructing perceived value
}

\author{
Ofir Turel ${ }^{\mathrm{a}, *}$, Alexander Serenko ${ }^{\mathrm{b}}$, Nick Bontis ${ }^{\mathrm{a}}$

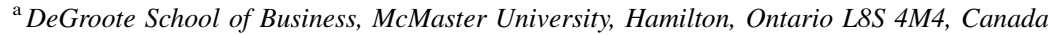 \\ ${ }^{\mathrm{b}}$ Faculty of Business Administration, Lakehead University, Thunder Bay, Ontario P7B 5E1, Canada \\ Received 22 June 2005; received in revised form 12 April 2006; accepted 26 October 2006 \\ Available online 28 November 2006
}

\begin{abstract}
Wireless value-added pay-per-use services, such as short messaging services (SMS), have attracted increased attention in recent years. Nevertheless, the extant literature has provided little insight into technology adoption of wireless pay-per-use services. Our study examined this adoption by combining marketing and IS perspectives through an empirical survey of 222 young-adult SMS users. It was hypothesized that perceived value would be a key multidimensional determinant of behavioral intentions. The paper therefore discusses a broadened conceptualization of technology adoption in which value tradeoffs (i.e., price, social, emotional and quality) are critical drivers in the adoption decision.
\end{abstract}

(C) 2006 Elsevier B.V. All rights reserved.

Keywords: Technology acceptance; Mobile commerce; Perceived value; Short messaging services (SMS); Value added services (VAS)

\section{Introduction}

Mobile services have diffused all over the globe. According to the International Telecommunication Union, by 2005 there were over 1.5 billion cell-phone users - about one-quarter of the world's population expected to send over 1 trillion text messages in the year. Even in North America, which was lagging the adoption of mobile services compared to Europe and Japan [36], wireless services captured a significant market share. In the United States, there were almost 200 million wireless service subscribers by the end of 2005 , and the penetration rates were expected to grow from around 65 to about $80 \%$ by 2009 [19]. Due to this surprising growth, mobile applications have required

\footnotetext{
* Corresponding author. Tel.: +1 905525 9140; fax: +1 9055218995 .

E-mail address: turelo@mcmaster.ca (O. Turel).
}

special attention from the research community, especially MIS scholars.

Recent years have brought intensified competition to the wireless sector. In North America, the telecommunications act of 1996 opened the mobile market for regulated competition and facilitated the entrance of new participants. This resulted in strong price competition for the voice market and a steady decline in average revenue per user (ARPU) [26]. To stay competitive and increase revenues, service providers turned to value added services (VAS), such as picture messaging and gaming [5]. Despite the attention given to VAS by wireless carriers, developers, and regulators, most of these services have not proved to be profitable. By 2003, VAS accounted for only 1.9 and $11.9 \%$ of the total ARPU in North America and worldwide, respectively [44].

Short messaging service (SMS) or text messaging is one of the most frequently used mobile services. It allows users to send and receive text messages of up to 160 characters to and from mobile devices. The text is 
entered by using a phone keypad or PC keyboard, and it may consist of words, numbers, or alphanumeric combinations. SMS was created as part of the Global Standard for Mobile Services (GSM) Phase 1 standard. It uses the network-signaling channel for data transmitting and receiving. Thus, from a service providers' perspective, SMS is an efficient communication medium which does not consume voice-communication channels and resources.

Currently, SMS is the main revenue generator within the mobile VAS domain [38]. The monthly global usage volume has grown from close to zero in 1999, to over 24 billion messages in 2003 [23]. Although Third Generation services promise even more innovative VAS, industry professionals forecast that person-toperson communications (picture messaging, instant messaging, etc.) will account for $46 \%$ of VAS revenues in 2009 , out of which, $50 \%$ will still be generated by SMS [41].

While almost any cell-phone user can utilize SMS these days, the teen/youth (ages 11-17 years) and youngadult (ages 18-25 years) markets lead their adoption and use. A survey of over 2000 users showed that $27 \%$ of North American teens and $43 \%$ of North American young adults used wireless text messaging at least once a month [6]. Since the young-adult group is the largest user segment, our study focused on these users.

User acceptance of SMS cannot be fully explained by the technology adoption models that already exist. A significant body of research supports the view that the use of any specific IS is determined by behavioral intentions to use it, whereas behavioral intentions are determined by users' perceptions regarding the system. The Theory of Reasoned Action (TRA) [20], the Theory of Planned Behavior (TPB) [1] and the Technology Acceptance Model (TAM) [15] are the most commonly applied ways of analyzing the behavior and perceptions of IS users. The validity and explanatory power of these models have been examined across many systems and contexts [28]. All of the contexts, however, have included applications and devices which were free for individual users, or for which they paid a one-time fee, with the daily use free of charge. In sharp contrast, SMS users are often charged for every text message sent. Therefore, additional factors should be considered.

In our study, we assumed that an overall assessment of value was a key determinant of behavioral intentions to employ pay-per-use information services, especially for SMS. While previous projects have examined only the monetary value dimension of mobile services (e.g., [47]), we assumed a broader view of value that included not only monetary but also emotional, social, and performance dimensions. To operationalize this broad view, the multidimensional 'perceived value' concept developed by Sweeney and Soutar [42] was adapted from marketing research; and its aggregated effect on the behavioral intentions of young adults to use SMS was examined through quantitative analyses of surveybased data. Thus, the following research questions were addressed in our investigation:

RQ1 Does the perceived value of short messaging services (i.e., the consumer's overall assessment of the utility of SMS based on perceptions of what is received and what is given) positively affect an individual's intentions to use them?

RQ2 What are the key value components that drive the adoption of short messaging services?

Overall, the convergence of marketing and MIS views was assumed to form a better understanding of SMS usage drivers by identifying important value dimensions in its adoption. Moreover, it was believed that our investigation would allow us to develop the theoretical foundations that explained the behavioral usage intentions towards IS under pay-per-use conditions, and to determine how and when value perceptions beyond efficiency and effectiveness were involved.

\section{Theoretical framework}

\subsection{Theoretical development}

If technology is not used, whether in organizational or personal settings, stakeholders do not harvest the benefits of this innovation but carry the cost of its implementation. In previous investigations, systems have generally been free of charge, and the social structures in which users operate have been ignored. Thus, individuals did not need to consider value tradeoffs when interacting with the system, nor did they have to take into account value components that were gained in any usage. While existing adoption models have captured the usefulness (or performance expectancy) and ease of use (or effort expectancy) of a system, insufficient consideration was given to other value tradeoffs. In most contexts, models did not address the financial, social desirability, quality, and enjoyment dimensions in a unified model.

Marketing literature, however, addresses such issues in consumer behavior studies. Specifically, this research aggregates perceptions about product benefits and tradeoffs under the concept of perceived value. This has been defined as a "consumer's overall assessment of 
the utility of a product (or service) based on perceptions of what is received and what is given" [54]. As opposed to the traditional MIS adoption views in which nothing, besides mental or minor physical efforts, is paid for the use of the system, the perceived value concept represents a comparison of the 'give' and 'take' components of using products and services.

We assumed that consumer behavior concepts, such as perceived value, could explain user adoption behavior because technology acceptance is a cognitive decision made by individuals for a specific IS. This process is like a consumer behavior process, because it focuses on the cognitive aspects of decision making about any product or service. It is also consistent with behavioral theories, such as the TRA, since perceived value is a context specific perception that may drive user attitudes and behaviors. Overall, for SMS, people must decide on their usage based on a broad range of value tradeoffs that form an assessment of value. For example, even if SMS is believed to be useful and easy to use, people may have a low overall value perception that will lead to low adoption when SMS seem too expensive compared to its benefits.

While some studies have hypothesize that the influence of customers' value perceptions on their service related behaviors is mediated through customer satisfaction (e.g., [21]), others have argued that perceived value, as a cognitive concept, has a direct impact on behavioral outcomes [17]. This has been empirically verified in several studies; e.g., [18] and [46]. Specifically, in the wireless services domain, a narrower conceptualization of perceived value was shown to directly affect intentions to adopt Third Generation mobile services [53]. Therefore, we made the following hypothesis:

Hypothesis 1. The overall perceived value of SMS is positively associated with behavioral intentions to use SMS.

Many marketing academics argue that the quality versus price tradeoff is considered by consumers using a value-for-money perspective (e.g., [2]). Others suggest that this view is too simplistic [7]. For example, intrinsic pleasure seeking, esthetic, and symbolic motives drive consumption [25].

Sweeney and Soutar suggested a view of value of consumer durable goods that had four dimensions: performance/quality, emotional, value-for-money, and social. The performancelquality dimension was a functional value that captured the utility resulting from quality perception and performance expectation. Emotional value was the utility derived from the feelings or affective states generated by a product. Value-for-money was a functional value dimension that encapsulated the utility derived from the product due to the reduction of its perceived short term and longer term costs. Social value was defined as the enhancement of a person's selfconcept provided by the product.

Based on this, a 19-item measure named PERVAL was developed to assess the dimensions of perceived value. This showed that the four value dimensions were distinct yet correlated, and that they impacted consumption decisions. An examination of criterion validity revealed that all four dimensions had some effect (varying from 0.19 to 0.62 ) on behavioral outcomes, such as willingness to buy and recommend the product. Moreover, it has been shown that using only a value-for-money measure accounts for only 23$29 \%$ of the variance, and using the four dimensions of value explains $48-68 \%$ of the variance in the behavioral outcomes.

While the study clearly demonstrated the direct effect of the perceptions on behavioral outcomes, the use of the dimensions as four independent components was considered somewhat inadequate. Because the prevailing definition of perceived value was "an overall assessment," the component level value perceptions should form an overall value, which in turn, would affect the outcome. That is, users are expected to make mental tradeoffs, which become the overall value. Furthermore, these components may not covary; for example, an increase in emotion does not imply a change in quality. Thus, it satisfies the statistical and conceptual conditions for a formative construct $[10,12]$. It has also been shown that the idea of perceived value as a second order factor with first-order components outperforms other value model configurations [32].

\subsection{Hypothesis development}

Given the theoretical and empirical superiority of the second order conceptualization of value, we aggregated the value components into a global value perception. As such, overall perceived value was treated as a molar perception [3] formed by four affective responses to SMS. We assumed that the four components would exert varying effects on the overall perceived value.

First, the performance/quality dimension (performance/quality value-PQV) reflects the design of the service, consistency, and the network quality. The importance of the concept of perceived quality has been recognized (e.g., [27]) and its indirect impact on behavioral outcomes has been validated [51]. Nevertheless, its effect on an overall value has not been explored. The service-oriented marketing literature has 
reported on studies that have shown that higher quality evaluations lead to higher overall value (e.g., $[4,8]$ ). Accordingly, we made the hypothesis that:

Hypothesis 2-1. The performance/quality dimension of perceived value of SMS is positively associated with the overall perceived value of SMS.

Second, the emotional dimension (perceived emotional value $[\mathrm{PEV}])$ reflects enjoyment, pleasure, and anxiety of using SMS. It has been argued that emotional components, such as enjoyment and anxiety, promote and impede the use of IS, respectively (e.g., [16,24]). In the marketing literature, it has been demonstrated that the emotional component is important in the overall value of service contexts [34,37]. Accordingly, it seemed that users who found the SMS enjoyable and emotionally fulfilling to use were more likely to develop a higher perceived overall value. As such, we made the following hypothesis:

Hypothesis 2-2. The emotional dimension of perceived value of SMS is positively associated with the overall perceived value of SMS.

Third, the value-for-money construct (perceived value for money [PVFM]) was expected to influence the overall perceived value of SMS, because it represented the main "take" component in the overall assessment. That is, the fee per use is charged and, in return, SMS users receive functional, emotional and social value. The MIS literature has treated monetary value or price as an overall value, rather than as a component of perceived value (e.g., [52]). In contrast, the marketing literature has repeatedly demonstrated that monetary value or price is only one component in a wide range of value tradeoffs (e.g., [29]). Thus, we proposed the hypothesis:

Hypothesis 2-3. The value-for-money dimension of perceived value of SMS is positively associated with the overall perceived value of SMS.

The social dimension (perceived social value [PSV]) is believed to impact the overall value assessment of SMS, since it reflects social approval and desirability of SMS usage. This captures self-concept enhancement, which is a non-instrumental driver for SMS adoption. Individuals may enhance their self-concept by using SMS, because the technology may be perceived as trendy and innovative, and this can signal that the user belongs to a particular social class. Such self-concept enhancements have been linked to the use of IS [40] and were seen as a perceived value component. Thus, we formed the hypothesis:
Hypothesis 2-4. The social dimension of perceived value of SMS is positively associated with the overall perceived value of SMS.

Prior MIS projects also identified a strong link between behavioral intentions (BI) and the actual use of almost all IS [30]. Accordingly, we proposed:

Hypothesis 3. Behavioral intentions to use SMS are positively associated with the actual usage of SMS.

The model including these hypothesized relationships is shown in Fig. 1.

To ascertain whether other factors affected the observed variations, we controlled the analysis for age and gender because these variables have been shown to affect relationships in past technology adoption studies. Men have been shown to be more pragmatic and task oriented, have lower concern for others, and present higher technology self-efficacy than women [49]. For age, younger users may place higher importance on extrinsic rewards and lower importance on ease of use, and are less likely to conform to others' opinions [35]. While we did not state formal hypotheses for these control variables, we included them in the analysis.

\section{Research methodology and results}

\subsection{Instrument development and data collection}

An empirical investigation of current SMS users was conducted. The questionnaire consisted of two parts. The first solicited demographic information such as age, sex, and utilized mobile services. The second presented questions pertaining to the proposed model. The questions for the perceived value were adapted from Sweeney and Soutar. Two questions measuring behavioral usage intentions were adapted from Technology Acceptance Model 2 [48]. To measure actual SMS usage, users were asked to self-report their average monthly expense on SMS and the number of messages they sent daily. A single negatively-worded question was included to reduce the probability of common method bias [39]. To address face validity, a group of business professors, doctoral students, and industry experts was asked to read and refine the questionnaire. Based on their feedback, several items were changed to reflect the purpose better. This pretest examination provided us reasonable surety of the validity of the scale items. The final instrument is given in Appendix A.

A group of 508 students in a fourth year undergraduate course at a large university was invited to help in this study; of the 508, 248 claimed to have utilized 


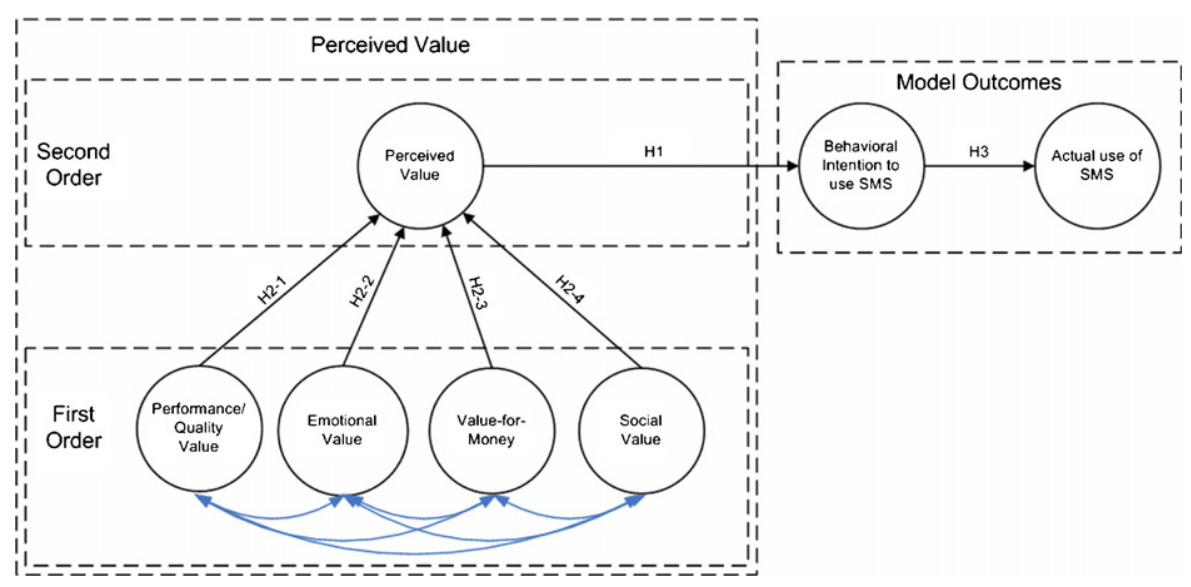

Fig. 1. The model of user acceptance of SMS.

SMS (48.8\%). Surveys were administered only to those who claimed experience with SMS. Of the 248, 229 questionnaires were returned $(92.3 \%)$; out of these, 7 were incomplete and therefore were excluded from the analysis. Thus, 222 usable responses were obtained from a non-random population of young-adults. 53.6\% of the respondents were female. Additional demographic and usage statistics are given in Table 1.

The descriptive analysis provided some confidence that our sample reasonably represented the target population (young-adult North American users). A comprehensive study of this market segment had previously shown that the average wireless phone bill was US\$ 55 per month, and that $7 \%$ of them spent more than US\$ 99 per month. The sample obtained in our study was somewhat more conservative, because the average phone bill was close to US\$ 46 and only $5.2 \%$ spend more than US\$ 99 a month on wireless services. With regards to SMS usage, our sample was slightly more advanced than findings from the market survey. While $43 \%$ of North American young adults use SMS and, on average, each sends one text message per day, almost $49 \%$ of our sample has used SMS and, on average, sent 1.6 messages per day. These differences may be attributed to the decline in service fees and changes in wireless service usage patterns from the time of the market survey (2003) to that of our study. Overall, the demographics and usage patterns of our sample did not substantially deviate from those of young-adult North American users.

\subsection{Analysis}

The structural and measurement models were tested by using PLS-Graph Version 03.00. This approach was chosen since it fits small-sample research and handles formative indicators [45]. In order to operationalize the second order factor, a repeated indicators approach (i.e., the hierarchical component model) was used [33]. This is suitable for PLS estimations [9], and as such, the second order perceived value factor was measured by the indicators of all the first-order perceived value factors.

An initial analysis was applied to a model controlling for age and gender. However, no significant effects of these control variables on the hypothesized relationships were observed.

\subsubsection{The measurement model}

A preliminary assessment of each constructs' reliability was conducted using Cronbach's alpha; all values were above 0.83 . Statistics of both measurement items and constructs are summarized in Table 2.

Table 1

Descriptive statistics

\begin{tabular}{|c|c|c|c|c|c|}
\hline & $n$ & Mean & Median & Minimum & Maximum \\
\hline Age & 222 & 22.58 & 23.00 & 19.00 & 25.00 \\
\hline Average number of text messages sent per day & 221 & 1.64 & 1.00 & 0.10 & 10.00 \\
\hline Average monthly bill for cellular services [US\$] & 212 & 45.92 & 38.40 & 4.00 & 104.00 \\
\hline Average monthly expense on SMS [US\$] & 182 & 2.35 & 1.60 & 0.80 & 14.40 \\
\hline
\end{tabular}


Table 2

Measurement model statistics

\begin{tabular}{|c|c|c|c|c|c|c|c|}
\hline Item & Mean & $\begin{array}{l}\text { Standard } \\
\text { deviation }\end{array}$ & $\begin{array}{l}\text { Factor } \\
\text { loading }\end{array}$ & $\begin{array}{l}\text { Residual } \\
\text { variance }\end{array}$ & $\begin{array}{l}\text { Item-total } \\
\text { correlations }\end{array}$ & $\begin{array}{l}\text { Cronbach's } \\
\text { alpha }\end{array}$ & $\begin{array}{l}\text { Internal consistency } \\
\text { (average variance extracted-AVE) }\end{array}$ \\
\hline PQV1 & 5.29 & 1.19 & 0.89 & 0.22 & 0.76 & 0.83 & $0.89(0.67)$ \\
\hline PQV2 & 4.81 & 1.22 & 0.84 & 0.30 & 0.64 & & \\
\hline PQV3 & 5.15 & 1.18 & 0.89 & 0.21 & 0.76 & & \\
\hline PQV4 & 5.33 & 1.34 & 0.64 & 0.60 & 0.52 & & \\
\hline PEV1 & 4.77 & 1.45 & 0.85 & 0.27 & 0.73 & 0.86 & $0.90(0.65)$ \\
\hline PEV2 & 4.06 & 1.60 & 0.84 & 0.30 & 0.73 & & \\
\hline PEV3 & 5.47 & 1.33 & 0.69 & 0.53 & 0.49 & & \\
\hline PEV4 & 4.04 & 1.48 & 0.85 & 0.27 & 0.79 & & \\
\hline PEV5 & 3.77 & 1.61 & 0.78 & 0.39 & 0.69 & & \\
\hline PVFM1 & 4.13 & 1.56 & 0.85 & 0.28 & 0.74 & 0.88 & $0.92(0.73)$ \\
\hline PVFM2 & 3.88 & 1.40 & 0.84 & 0.30 & 0.73 & & \\
\hline PVFM3 & 4.18 & 1.45 & 0.90 & 0.20 & 0.80 & & \\
\hline PVFM4 & 4.18 & 1.44 & 0.84 & 0.30 & 0.69 & & \\
\hline PSV1 & 3.01 & 1.62 & 0.91 & 0.18 & 0.79 & 0.93 & $0.95(0.82)$ \\
\hline PSV2 & 2.72 & 1.58 & 0.94 & 0.12 & 0.89 & & \\
\hline PSV3 & 2.82 & 1.56 & 0.92 & 0.15 & 0.87 & & \\
\hline PSV4 & 2.66 & 1.56 & 0.86 & 0.26 & 0.79 & & \\
\hline BI1 & 4.97 & 1.42 & 0.96 & 0.09 & 0.83 & 0.91 & $0.96(0.92)$ \\
\hline BI2 & 5.10 & 1.42 & 0.96 & 0.08 & 0.83 & & \\
\hline Mess sent & 1.64 & 2.13 & 0.89 & 0.20 & \multirow{2}{*}{\multicolumn{3}{|c|}{ NA (actual usage is a formative construct) }} \\
\hline SMS Exp & 2.94 & 3.25 & 0.76 & 0.43 & & & \\
\hline
\end{tabular}

Virtually, all factor loadings exceeded a threshold value of 0.7. Only two items (PQV4 and PEV3) obtained a loading slightly below this, but were retained because all of the item-to-total correlation coefficients met the recommended cut-off value of 0.35 with relatively low residual variances. Fornell and Larcker's [22] measures of internal consistency and convergent validity of all constructs were greater than 0.7 and 0.5 , respectively. The actual usage of SMS had two formative indicators: the actual number of SMS sent per day and total monthly
SMS expenses; all other constructs were operationalized with reflective indicators.

Table 3 shows the loadings and cross-loadings of the observed variables with the model's constructs. An inspection of the table shows that there is confidence in the discriminant and convergent validity of the constructs with no evident cross-loadings.

Additional assessment of discriminant validity was conducted by comparing the average variance extracted from each construct with its communal variances shared

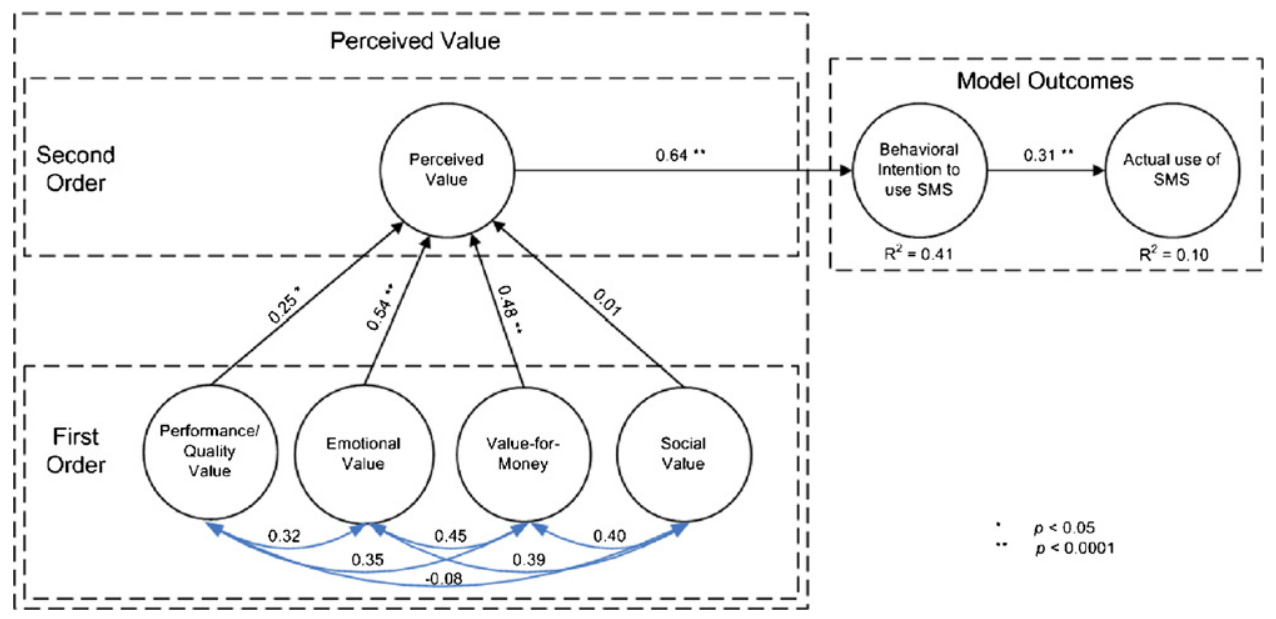

Fig. 2. The structural model. 
Table 3

Matrix of loadings and cross-loadings

\begin{tabular}{lrllrll}
\hline & PQV & PEV & PVFM & \multicolumn{1}{l}{ PSV } & BI & USE \\
\hline PQV1 & $\mathbf{0 . 8 9}$ & 0.30 & 0.35 & -0.07 & 0.33 & 0.23 \\
PQV2 & $\mathbf{0 . 8 4}$ & 0.31 & 0.30 & 0.03 & 0.33 & 0.26 \\
PQV3 & $\mathbf{0 . 8 9}$ & 0.26 & 0.31 & -0.07 & 0.33 & 0.18 \\
PQV4 & $\mathbf{0 . 6 4}$ & 0.13 & 0.12 & -0.25 & 0.14 & 0.09 \\
PEV1 & 0.28 & $\mathbf{0 . 8 5}$ & 0.32 & 0.17 & 0.39 & 0.42 \\
PEV2 & 0.15 & $\mathbf{0 . 8 4}$ & 0.26 & 0.29 & 0.38 & 0.35 \\
PEV3 & 0.42 & $\mathbf{0 . 6 8}$ & 0.41 & -0.04 & 0.44 & 0.30 \\
PEV4 & 0.15 & $\mathbf{0 . 8 5}$ & 0.35 & 0.50 & 0.36 & 0.32 \\
PEV5 & 0.11 & $\mathbf{0 . 7 9}$ & 0.30 & 0.58 & 0.26 & 0.25 \\
PVFM1 & 0.27 & 0.32 & $\mathbf{0 . 8 5}$ & 0.06 & 0.37 & 0.10 \\
PVFM2 & 0.16 & 0.39 & $\mathbf{0 . 8 4}$ & 0.15 & 0.38 & 0.16 \\
PVFM3 & 0.44 & 0.36 & $\mathbf{0 . 9 0}$ & 0.08 & 0.48 & 0.17 \\
PVFM4 & 0.29 & 0.46 & $\mathbf{0 . 8 4}$ & 0.19 & 0.46 & 0.27 \\
PSV1 & -0.01 & 0.40 & 0.18 & $\mathbf{0 . 9 1}$ & 0.17 & 0.22 \\
PSV2 & -0.09 & 0.31 & 0.13 & $\mathbf{0 . 9 4}$ & 0.11 & 0.14 \\
PSV3 & -0.11 & 0.36 & 0.12 & $\mathbf{0 . 9 2}$ & 0.14 & 0.20 \\
PSV4 & -0.13 & 0.31 & 0.07 & $\mathbf{0 . 8 6}$ & 0.15 & 0.11 \\
BI1 & 0.33 & 0.48 & 0.48 & 0.15 & $\mathbf{0 . 9 6}$ & 0.30 \\
BI2 & 0.36 & 0.51 & 0.48 & 0.16 & $\mathbf{0 . 9 6}$ & 0.29 \\
MESSS & 0.20 & 0.36 & 0.19 & 0.21 & 0.26 & $\mathbf{0 . 8 9}$ \\
EXPNSMS & 0.21 & 0.35 & 0.16 & 0.12 & 0.24 & $\mathbf{0 . 7 9}$ \\
\hline
\end{tabular}

Table 4

Correlations and square roots of average variance extracted of the firstorder constructs

\begin{tabular}{lrrrrrr}
\hline & \multicolumn{1}{c}{ PQV } & PEV & PVFM & PSV & BI & Use \\
\hline PQV & $\mathbf{0 . 8 2}$ & & & & & \\
PEV & 0.32 & $\mathbf{0 . 8 0}$ & & & & \\
PVFM & 0.35 & 0.45 & $\mathbf{0 . 8 5}$ & & & \\
PSV & -0.08 & 0.39 & 0.14 & $\mathbf{0 . 9 1}$ & & \\
BI & 0.36 & 0.52 & 0.50 & 0.16 & $\mathbf{0 . 9 6}$ & \\
Use & 0.24 & 0.41 & 0.21 & 0.19 & 0.31 & $\mathbf{0 . 5 6}$ \\
\hline
\end{tabular}

with other constructs. Table 4 gives the inter-construct correlations (below the diagonal) and the square roots of the average variance extracted (on the diagonal) of the first-order constructs. This table shows that the square root of the average variance extracted for all first-order factors was higher than their shared variances. This reaffirmed the discriminant validity of the model constructs.

\subsubsection{The structural model}

Bootstrapping with 200 re-samples was performed to derive $t$-statistics for the structural paths. This number of re-samples was sufficient for obtaining adequate parameter estimates [13]. The corresponding $p$-values and construct loadings are given in Fig. 2.

The results indicated that five hypotheses were supported and one was rejected (see Table 5). As theorized, users' perceptions of both emotional and monetary values were strong predictors of their overall value assessment. Perceived quality had a moderate relationship with the aggregated perceived value. Perceived social value, however, had no impact on users' overall value assessment of wireless text messaging services. The global value assessment strongly affected behavioral usage intentions. Consistent with prior research, it was found that behavioral intentions to use SMS lead to its actual use.

In order to estimate the predictive power of the four value components, their effect sizes were calculated [11]. For this, one first-order construct was removed at a time, the model was re-estimated, and $R$-square values of the second-order perceived value construct and BI were recorded. As recommended by Cohen [14], the effect size values of $0.02,0.15$, and 0.35 correspond to a predictor that has a small, medium, or large effect at the structural level. In our study, the effect sizes of PQV, PEV, PVFM, and PSV on the overall perceived value were $0.27,0.93,0.87$, and 0.00 . Thus, PQV has a medium effect, and PEV and PVFM have large effects. The effect sizes of PQV, PEV, PVFM, and PSV on users behavioral intentions (mediated through the overall value assessment) were $0.02,0.07,0.07$, and 0.00 . Therefore, PQV, PEV, and PVFM had small-medium effects on users' behavioral intentions. This indicated that there was no single value component that contributed significantly to the predictive power of the model. Instead, it was the combination of the PQV, PEV, and PVFM constructs that explained more than

Table 5

Hypotheses testing

\begin{tabular}{|c|c|c|c|c|}
\hline Hypothesis & Beta & $t$-Value & $p$-Value & Outcome \\
\hline Hypothesis $1(\mathrm{H} 1)$ : overall perceived value-intentions & 0.64 & 14.56 & $<0.0001$ & Supported \\
\hline Hypothesis 2-1 (H2-1): perceived quality—overall perceived value & 0.25 & 2.18 & $<0.05$ & Supported \\
\hline Hypothesis 2-2 (H2-2): perceived emotional value-overall perceived value & 0.54 & 4.22 & $<0.0001$ & Supported \\
\hline Hypothesis 2-3 (H2-3): perceived value-for-money-overall perceived value & 0.48 & 4.46 & $<0.0001$ & Supported \\
\hline Hypothesis 2-4 (H2-4): perceived social value-overall perceived value & 0.01 & 0.07 & NA & Rejected \\
\hline Hypothesis 3 (H3): intentions-usage & 0.31 & 5.50 & $<0.0001$ & Supported \\
\hline
\end{tabular}


$40 \%$ of user behavioral intentions towards the employment of SMS.

\section{Discussion}

As a result of the PLS analysis, five hypotheses were supported and one was rejected. We believe that the combination of questions from both marketing and MIS fields did not have a negative impact on the measurement properties of each scale.

\subsection{Implications for research}

First and foremost, the model was different from other adoption models because it included both system (situation-specific) and value-for-money measures that seemed to be highly relevant to the acceptance of SMS. The Unified Theory of Acceptance and Use of Technology (UTAUT) [50] further suggested that intentions to use IT were influenced by performance expectancy, effort expectancy, and facilitating conditions. However, in the pay-per-use context, factors that relate to the cost of system usage become essential.

Second, perceived value of SMS was an important predictor of people's behavioral intentions. This demonstrated the use of joined marketing and MIS viewpoints and suggested that the existing marketing models may be adapted to the investigation of user acceptance of various IT under value-exchange conditions.

Third, perceptions of positive emotions were the key factors influencing usage intentions towards SMS. Indeed, many people may utilize SMS for purely intrinsic reasons without feeling that there are effectiveness or efficiency outcomes. Specifically, a path coefficient of $0.35(p<0.001)$ between perceived enjoyment and intentions to use instant messaging was found in a recent study [31]. Interestingly, a similar indirect effect $(0.54 \times 0.64=0.35)$ was obtained between perceived emotional value and intentions to use SMS in our project.

Fourth, the price is a significant predictor of the employment of an SMS technology on a pay-per-use basis: many SMS users are price sensitive. The degree of perceived quality of SMS was believed to have a moderate effect on usage intentions; however, the extent of perceived social value was found to have no impact on users' overall perceived value and future usage of SMS.

Fifth, consistent with prior MIS studies, it was found that usage intentions lead to the usage of SMS. The path coefficient of 0.31 between BI and Use is coherent with those of previous investigations (e.g., [43]).
Sixth, the aggregation of three constructs pertaining to the domain of perceived value of SMS, such as performance/quality, value-for-money and emotions, explained more than $40 \%$ of the variance in user intentions to utilize this technology. As such, no single construct contributed significantly to the predictive power of the model, but together, they relatively adequately described the phenomenon of SMS usage.

Last, Sweeney and Soutar suggested that "the majority of the PV scale is likely to remain appropriate for a variety of contexts with only quality items likely to need adaptation for nondurable products." Our study demonstrated that the PV scale, slightly adapted to the examined context had good psychometric properties in the short messaging services context.

\subsection{Implications for practice}

Our study provided practical insights also for industry. Understanding what drives the adoption of SMS is critical to foster technology diffusion. This is true especially in countries with relatively low SMS adoption rates. Furthermore, the insights shed some light on potential avenues of action for promoting the diffusion of other mobile value added services, such as multimedia messaging services (MMS), mobile downloads (ringtones and icons), mobile games, etc. By addressing the key value dimensions, mobile service developers and service providers can drive the acceptance of SMS as well as the penetration of other mobile value added services.

Based on our rejection of the link between perceived social value and overall perceived value, marketers should not concentrate on the promotion of perceived image of SMS users. Other aspects and consequences should be advertised. The fun of using the service and the low-price of the medium relative to its value should be emphasized.

In addition to the recommendations for mobile service providers and developers, this study provided some potential avenues of action for wired pay-per-use information services providers like eBay and iTunes. They may utilize our model to examine the salient value drivers in their context.

\subsection{Limitations}

The limitations mostly relate to external validity, since the population of SMS users were from only one university in one country and a convenience sampling method was utilized. As such, the results are generalizable only for young adult North Americans. 


\section{Conclusion}

The industry of mobile value added services, such as picture messaging and gaming, is growing. In order to foster the acceptance of these services, it is important to understand the underlying motives of user behavior. Our study enhanced understanding of the interaction of users with mobile value added services and provided valuable insights for industry professionals.

With a quarter of the world already penetrated by mobile phone users, SMS use is exploding. The potential in North America and China is staggering. With the right vision, and bold, forward-thinking strategies, SMS providers stand to realize enormous gains.

SMS has become a commodity offering: one where demand is still growing. Telecom executives will always look for ways to drive down the cost of service delivery. This will free up resources that can be routed towards developing new and innovative VAS that will help secure their position in the marketplace.

\section{Acknowledgements}

The authors are very grateful to the editor and the anonymous reviewers of Information and Management who provided very valuable feedback on an earlier version of this paper

\section{Appendix A. Research instrument}

\section{A.1. Part A: Demographics and short messaging services (SMS) usage}

1. What is the average number of text messages (SMS) you send per day (messages/day)?

2. What is your average monthly bill for this phone (US\$)?

3. What is your average monthly expense on SMS (US\$)? (i.e., the portion of the monthly bill that is for sending and receiving SMS).

4. What is your age (years)?

5. Your sex: $\square$ male $\square$ female

\section{A.2. Part B: Perceived value of SMS services}

Please answer all questions below with respect to your actual experience with SMS services:

All items apply a 7-item Likert scale, from strongly disagree (1) to strongly agree (7):

PQV1 SMS services have consistent quality.

PQV2 SMS services are well designed.
PQV3 SMS services have an acceptable standard of quality.

PQV4 The quality of SMS services is NOT provided consistently.

PEV1 SMS services are ones that I enjoy.

PEV2 SMS services make me want to use them.

PEV3 SMS services are ones that I feel relaxed about using.

PEV4 The use of SMS services makes me feel good.

PEV5 The use of SMS services gives me pleasure.

PVFM1 SMS services are reasonably priced.

PVFM2 SMS services offer value for money.

PVFM3 The quality of SMS services is good relative to the price.

PVFM4 SMS services are economical.

PSV1 The use of SMS services helps me feel acceptable.

PSV 2 The use of SMS services improves the way I am perceived.

PSV 3 The fact I use SMS services makes a good impression on other people.

PSV 4 The use of SMS services gives me social approval.

BI1 Assuming I have access to the SMS services of my current provider, I intend to use them in future.

BI2 Given that I have access to the SMS services of my current provider, I predict that I would use them in future.

\section{References}

[1] I. Ajzen, From intentions to actions: a theory of planned behavior, in: J. Kuhl, J. Beckman (Eds.), Action-Control: From Cognition to Behavior, Springer-Verlag, 1985, pp. 11-39.

[2] E.W. Anderson, C. Fornell, Foundations of the American Customer Satisfaction Index, Total Quality Management \& Business Excellence 11 (7), 2000, pp. 869-882.

[3] R.P. Bagozzi, Expectancy-value attitude models: an analysis of critical theoretical issues, International Journal of Research Marketing 2 (1), 1985, pp. 43-60.

[4] J. Baker, A. Parasuraman, D. Grewal, G.B. Voss, The influence of multiple store environment cues on perceived merchandise value and patronage intentions, Journal of Marketing 66 (2), 2002, pp. 120-141.

[5] L. Barabee, Carriers Make a Play in Wireless Entertainment, The Yankee Group, September 2003.

[6] L. Barrabee, Wireless Market Segmentation: The "Who's Who" From the 2003 Mobile User Surveys, The Yankee Group, October 9, 2003.

[7] R.N. Bolton, J.H. Drew, A multistage model of consumers' assessments of service quality and value, Journal of Consumer Research 17 (3), 1991, pp. 375-384.

[8] M.K. Brady, C.J. Robertson, An exploratory study of service value in the USA and Ecuador, International Journal of Service Industry Management 10 (5), 1999, pp. 469-486. 
[9] W.W. Chin, Overview of the PLS Method, University of Houston, 1997 last accessed: December 31, 2005 at: http://discnt.cba.uh.edu/chin/PLSINTRO.HTM.

[10] W.W. Chin, Issues Opinion on Structural Equation Modeling, MIS Quarterly 22 (1), 1998, pp. vii-xi.

[11] W.W. Chin, The partial least squares approach for structural equation modeling, in: G.A. Marcoulides (Ed.), Modern Methods for Business Research, Lawrence Erlbaum Associates, Mahwah, NJ, 1998, pp. 295-336.

[12] W.W. Chin, Partial Least Squares for Researchers: An Overview and Presentation of Recent Advances Using the PLS Approach, 2000 last accessed: April 5, 2006 at: http://disc-nt.cba.uh.edu/ chin/icis2000plstalk.pdf.

[13] W.W. Chin, PLS-Graph User's Guide, Version 3.0, Soft Modeling Inc., 2001.

[14] J. Cohen, Statistical Power Analysis for the Behavioral Sciences, Lawrence Erlbaum Associates, Hillsdale, NJ, 1988.

[15] F.D. Davis, Perceived usefulness, perceived ease of use and user acceptance of information technology, MIS Quarterly 13 (3), 1989, pp. 319-340.

[16] F.D. Davis, R.P. Bagozzi, P.R. Warshaw, Extrinsic and intrinsic motivation to use computers in workplace, Journal of Applied and Social Psychology 22 (14), 1992, pp. 1111-1132.

[17] W. Dodds, K.B. Monroe, D. Grewal, Effects of price, brand and store information on buyers' product evaluation, Journal of Marketing Research 28 (3), 1991, pp. 307-319.

[18] A. Eggert, W. Ulaga, Customer perceived value: a substitute for satisfaction business markets? The Journal of Business \& Industrial Marketing 17 (2/3), 2002, pp. 107-118.

[19] eMarketer, The Mobile Future, eMarketer Report, September 20, 2005.

[20] M. Fishbein, I. Ajzen, Belief Attitude, Intention and Behavior: An Introduction to Theory and Research, Addison-Wesley, Reading, MA, USA, 1975.

[21] C. Fornell, M.D. Johnson, E.W. Anderson, J. Cha, B.E. Bryant, The American Customer Satisfaction Index: nature, purpose, and findings, Journal of Marketing 60 (7), 1996, pp. 7-18.

[22] C. Fornell, D.F. Larcker, Evaluating structural equation models with unobservable variables and measurement error, Journal of Marketing Research 18 (1), 1981, pp. 39-50.

[23] GSM Association, GSMA Statistics Q1 04, GSM Association, Dublin, Ireland, 2004.

[24] G. Hackbarth, V. Grover, M.Y. Yi, Computer playfulness and anxiety: positive and negative mediators of the system experience effect on perceived ease of use, Information \& Management 40 (3), 2003, pp. 221-232.

[25] M.B. Halbrook, E. Hirschman, The experiential aspects of consumption: consumption fantasies, feelings and fun, Journal of Consumer Research 9 (2), 1982, pp. 132-140.

[26] M. Hatton, Pricing Becomes the Keystone of Mobile Operators' Consumer Strategy, The Yankee Group, October 2003.

[27] W.J. Kettinger, C.C. Lee, Zones of tolerance: alternative scales for measuring information systems service quality, MIS Quarterly 29 (4), 2005, pp. 607-623.

[28] W.R. King, J. He, A meta-analysis of the technology acceptance model, Information and Management 43 (6), 2006, pp. 740-755.

[29] J. Lapierre, Customer perceived value in industrial contexts, Journal of Business \& Industrial Marketing 15 (2/3), 2000, pp. 122-140.

[30] P. Legris, J. Ingham, P. Collerette, Why do people use information technology? A critical review of the technology acceptance model Information \& Management 40 (3), 2003, pp. 191-204.
[31] D. Li, P.Y.K. Chau, H. Lou, Understanding individual adoption of instant messaging: an empirical investigation, Journal of the Association for Information Systems 6 (4), 2005, pp. 102-129.

[32] C.H. Lin, P.J. Sher, H.Y. Shih, Past progress and future directions in conceptualizing customer perceived value, International Journal of Service Industry Management 16 (3-4), 2005, pp. 318336.

[33] J.-B. Lohmoller, Latent Variable Path Modeling with Partial Least Squares, Physica-Verlag, Heidelberg, Germany, 1989.

[34] C. Mathwick, N. Malhotra, E. Rigdon, Experiential value: conceptualization, measurement and application in the catalog and Internet shopping environment, Journal of Retailing 77 (1), 2001, pp. 39-56.

[35] M.G. Morris, V. Venkatesh, Age differences in technology adoption decisions: implications for a changing work force, Personnel Psychology 53 (2), 2000, pp. 375403.

[36] S. Okazaki, What do we know about mobile Internet adopters? A cluster analysis Information \& Management 43 (2), 2006, pp. 127-141.

[37] J.F. Petrick, Development of a multi-dimensional scale for measuring the perceived value of a service, Journal of Leisure Research 34 (2), 2002, pp. 119-134.

[38] S. Pittet, Forecast: Mobile Data Services, Western Europe, 2001-2008, The Gartner Group, 2004.

[39] P.M. Podsakoff, S.B. MacKenzie, J.-Y. Lee, N.P. Podsakoff, Common method biases in behavioral research: a critical review of the literature and recommended remedies, Journal of Applied Psychology 88 (5), 2003, pp. 879903.

[40] C.D. Schewe, W.R. Dillon, Marketing information system utilization: an application of self-concept theory, Journal of Business Research 6 (1), 1978, pp. 67-79.

[41] Strategy Analytics, Cellular Data Forecast Model (2004-2009), Strategy Analytics, 2004.

[42] J. Sweeney, G.N. Soutar, Consumer perceived value: the development of a multiple item scale, Journal of Retailing 77 (2), 2001, pp. 203-220.

[43] S. Taylor, P.A. Todd, Understanding information technology usage: a test of competing models, Information Systems Research 6 (2), 1995, pp. 144-176.

[44] The Yankee Group, Global Wireless/ Mobile Forecast: The Yankee Group Report, 2004.

[45] R.D. Thomas, I.R.R. Lu, M. Cedzynski, Partial least squares: a critical review and a potential alternative, in: Proceedings of the Administrative Sciences Association of Canada (ASAC) Conference, Toronto, Ont., Canada, 2005.

[46] K. Toften, S.O. Olsen, The relationships among quality, cost, value and use of export market information: an empirical study, Journal of International Marketing 12 (2), 2004 , pp. 104-131.

[47] O. Turel, A. Serenko, Satisfaction with mobile services in Canada: an empirical investigation, Telecommunications Policy 30 (5-6), 2006, pp. 314-331.

[48] V. Venkatesh, F.D. Davis, A theoretical extension of the Technology Acceptance Model: four longitudinal field studies, Management Science 46 (2), 2000, pp. 186-204.

[49] V. Venkatesh, M.G. Morris, Why don't men ever stop to ask for directions? Gender, social influence, and their role in technology acceptance and usage behavior MIS Quarterly 24 (1), 2000, pp. $115-139$. 
[50] V. Venkatesh, M.G. Morris, G.D. Davis, F.D. Davis, User acceptance of information technology: toward a unified view, MIS Quarterly 27 (3), 2003, pp. 425-478.

[51] B.H. Wixom, P.A. Todd, A theoretical integration of user satisfaction and technology acceptance, Information Systems Research 16 (1), 2005, pp. 85-102.

[52] J.-H. Wu, S.-C. Wang, What drives mobile commerce? An empirical evaluation of the revised technology acceptance model Information \& Management 42 (5), 2005, pp. 719-729.

[53] X. Xin, A model for $3 G$ adoption, in: Proceedings of the Tenth Americas Conference on Information Systems, New York, NY, USA, 2004.

[54] V.A. Zeithaml, Consumer perceptions of price, quality and value: a means-end model and synthesis of evidence, Journal of Marketing 52 (3), 1988, pp. 2-22.

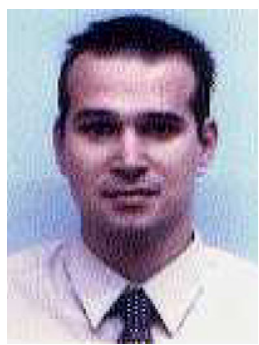

Ofir Turel is a $\mathrm{PhD}$ candidate at the DeGroote School of Business, McMaster University, Canada. He holds a BSc in industrial engineering and an MBA in technology management. Before joining the $\mathrm{PhD}$ program he has held senior positions in the information technology and telecommunications industries. His research interests include behavioral issues in the domains of online collaboration and mobile services. His award-winning work has been published in several peerreviewed journals and presented at various international conferences.

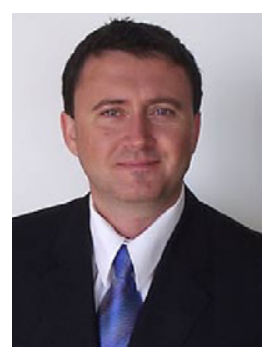

Alexander Serenko is an assistant professor of management information systems at the Faculty of Business Administration, Lakehead University, Canada. He holds an MSc in computer science, an MBA in electronic business, and a $\mathrm{PhD}$ in management science/systems. Dr. Serenko's research interests pertain to user technology adoption, knowledge management, and innovation. Alexander's articles appeared in various refereed journals, and his papers received awards at Canadian and international conferences.

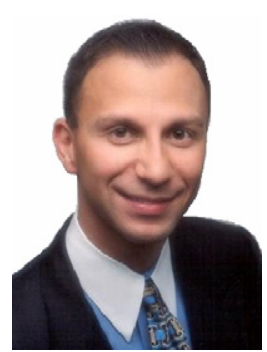

Nick Bontis is associate professor of strategic management at the DeGroote School of Business, McMaster University in Hamilton (Canada). He has published a variety of research papers in the fields of knowledge management, intellectual capital and new technology. He is also a well known consultant and professional speaker to corporate and government clients worldwide. 